\title{
Analysis of death rates in the population aged 60 years and over of Greater Glasgow by postcode sector of residence
}

\author{
DAVID HUME' AND JOHN WOMERSLEY ${ }^{2}$ \\ From the Chief Executive's Department, ${ }^{1}$ Strathclyde Regional Council, and Community Medicine Specialist, ${ }^{2}$ \\ Greater Glasgow Health Board
}

SUMMARY Using computer tapes of death registrations for the period 1980-2, and paper copy of population data for the 1981 census, death rates were calculated for the population resident in each of the 112 postcode sectors that make up the area served by the Greater Glasgow Health Board. Rates were calculated for both sexes in combination for each of the age groups 60-64, 65-69, $70-74,75-79,80-84$, and 85 years and over. The difference in the mean death rate for the 22 postcodes in the quintile with the highest rates and the 22 postcodes in the quintile with the lowest rates was just over twofold in the 60-64 age group, just under twofold in the 65-84 age groups, but only $1 \cdot 2$-fold in the age group 85 years and over. There was marked consistency between the various age groups in the mortality rating for the postcode sectors, the postcode sectors with the highest death rates being located entirely in the more disadvantaged areas of the city and suburbs. The geographical mortality pattern for the older population was very similar to that (standardised for age and sex) in the 15-59 year age group.

The availability of age-specific population data for 1981 by postcode sector of residence provided the opportunity of calculating mortality rates for relatively small areas within the health authorities in Scotland. It is known that within the Greater Glasgow Health Board standardised mortality rates vary between different communities, there being considerably greater mortality in areas of socioeconomic deprivation. The objective of the present investigation was to assess whether the observed geographical variation was consistent for all age groups, and to determine whether there was an age limit above which this variation was no longer apparent. This paper is concerned with the population aged 60 years and over.

\section{Method}

The geographical area investigated was that served by the Greater Glasgow Health Board. This comprises the five complete local government districts of Glasgow City (population about 755 000), Bearsden \& Milngavie (39 000),
Clydebank (52 000), Eastwood (53 000), and Strathkelvin $(87000)$ with a total population of about 987000 . The geographical unit for analysis was the postcode sector, that is, the full postcode minus the two terminal letters, of which there are some 157 complete or partial sectors within the Greater Glasgow Health Board area. The total population of residents (private households and communal establishments) in the six age groups $60-64,65-69,70-74,75-79,80-84$, and 85 years and over was determined for each postcode sector from the Small Area Statistics of the 1981 Census.

The total number of deaths over the period 1980-2 was extracted from computer tapes supplied by the General Register Office (Scotland) to the Chief Administrative Medical Officers of the Scottish health boards. These deaths were also sorted to postcode sector of usual residence.

The numerator and denominator populations in each postcode sector and each partial sector should match exactly, including those postcode sectors that include a long-stay institution, thus permitting the calculation of a valid rate. However, there may be 
some inconsistency in the methods used by the census respondent and by the Registrars of deaths in the way in which individuals were classified as being normally resident in a communal establishment or institution. ${ }^{*}$

In order to have sufficient numbers of deaths, men and women were included together. Where there were less than 20 deaths for any age group in any postcode sector, the postcode sector was amalgamated with an adjacent postcode sector, on the basis of similarity of the environment and socioeconomic characteristics of the population. This reduced the number of geographical units to 112 .

For each age group and each postcode sector or aggregate a three-year mortality rate was calculated. For each of the six age groups the postcode sector or aggregate was then ranked from the lowest to the highest mortality rate over the three-year period. The 112 ranked postcode sectors (or aggregates) were then grouped into five 'quintiles', the highest quintile comprising the 22 or so postcodes with the highest rates, and the lowest quintile comprising the 22 or so postcodes with the lowest rates.

\section{Results}

For each age group there were considerable differences in death rates between the postcode sectors. Death rates were highest in most of the older inner city areas and in some of the peripheral post-war local authority housing developments. Death rates were much lower in the relatively few areas of private housing within the city of Glasgow and in the more affluent suburbs (comprising all of Eastwood, Bearsden \& Milngavie, and parts of Strathkelvin local government districts).

The mean death rates for those postcode areas in the highest and lowest quintiles are given for each age group in table 1 . The difference in death rate between the areas with the highest and lowest death rates was just over twofold in the age group 60-64 years, and just under twofold in the age groups $65-69,70-74$, $75-79$, and 80-84. In the oldest age group (85 years and over) the difference was much smaller; one possible explanation for this is that the low mortality areas may have a higher proportion of very elderly people (say, 90 years and over) in this age group, thus increasing the overall death rate. This means that for

\footnotetext{
* On death certificates the institutional postcode is used if the individual has been resident in hospital or an institution for 12 months or more, unless the informant insists on the home postcode. On census forms, residents of homes for epileptics, incurables, blind, deaf and dumb, mentally handicapped children or the elderly receive the institutional postcode irrespective of the length of stay. Patients or residents in convalescent homes, general, maternity or special hospitals, homes for unmarried mothers, general nursing homes, sanatoria boarding schools, student halls of residence, and list D schools use the home postcode. Patients or residents of chronically sick and psychiatric hospitals and prisons use the institutional code if they have been resident for six months or longer, otherwise the home postcode is used.
}

Table 1 Mean annual death rates (per 1000 relevant population) for postcode areas in the highest and lowest mortality quintiles

\begin{tabular}{llllllll}
\hline \multicolumn{7}{l}{ Age group (years) } \\
\cline { 2 - 7 } \begin{tabular}{l} 
Postcode area \\
\cline { 2 - 7 }
\end{tabular} & $60-64$ & $65-69$ & $70-74$ & $75-79$ & $80-84$ & $85+$ \\
\hline $\begin{array}{c}\text { Highest quintile for } \\
\text { mortality }\end{array}$ & 33 & 47 & 72 & 103 & 168 & 306 \\
$\begin{array}{c}\text { Lowest quintile for } \\
\text { mortality }\end{array}$ & 15 & 28 & 41 & 62 & 93 & 256 \\
\begin{tabular}{l} 
Ratio high:low \\
\hline
\end{tabular} & 2.2 & 1.7 & 1.8 & 1.7 & 1.8 & 1.2 \\
\hline
\end{tabular}

people over the entire age range $60-84$ years, residents of the 'higher' quintile of postcode sectors have about twice the likelihood of dying in any one year compared with residents of areas in the 'lowest' quintile. Each of the major causes of death (ischaemic heart disease, malignant disease, and cerebrovascular disease) contributed to these differences.

There was marked consistency in the ranking of death rates between the different age groups in each $\stackrel{\mathbb{D}}{\circ}$ postcode sector, particularly in the four age groups $\stackrel{\mathcal{O}}{+}$ between 60 and 79 years. Thus the areas with the 0 iv highest death rates for those aged 60-64 years usually also had the highest rates for the age groups $\stackrel{\square}{\mathbb{Q}}$ 을

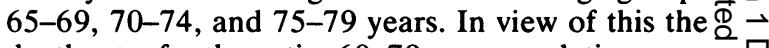
death rates for the entire $60-79$ year population were $\overline{0} \mathbb{D}_{\mathbb{D}}$ calculated and ranked for each postcode area. Figure 1 is a map of the Greater Glasgow Health Board area and of its constituent postcode sectors which shows the areas in the highest and lowest quintiles for mortality. For the purposes of constructing the map, the quintiles were calculated to produce approximately equal populations rather than approximately equal numbers of postcode areas, and so the 'high' and 'low' areas depicted each represent a total population of about 195000 (the total population resident within the Greater Glasgow Health Board area being 987 000).

\section{Discussion}

The area served by the Greater Glasgow Health Board extends to about 55000 hectares (132000 acres) and includes inner city, rural, and suburban populations of very different types. The range of social conditions includes both the most deprived and the most affluent areas and represents in microcosm almost the full spectrum of social circumstances found in the United Kingdom. The principal finding of this study is that over the age range $60-84$ years approximately twofold differences can be demonstrated between the $20 \%$ of the population resident in postcode sectors with the highest mortality rates and the $20 \%$ resident in postcode 


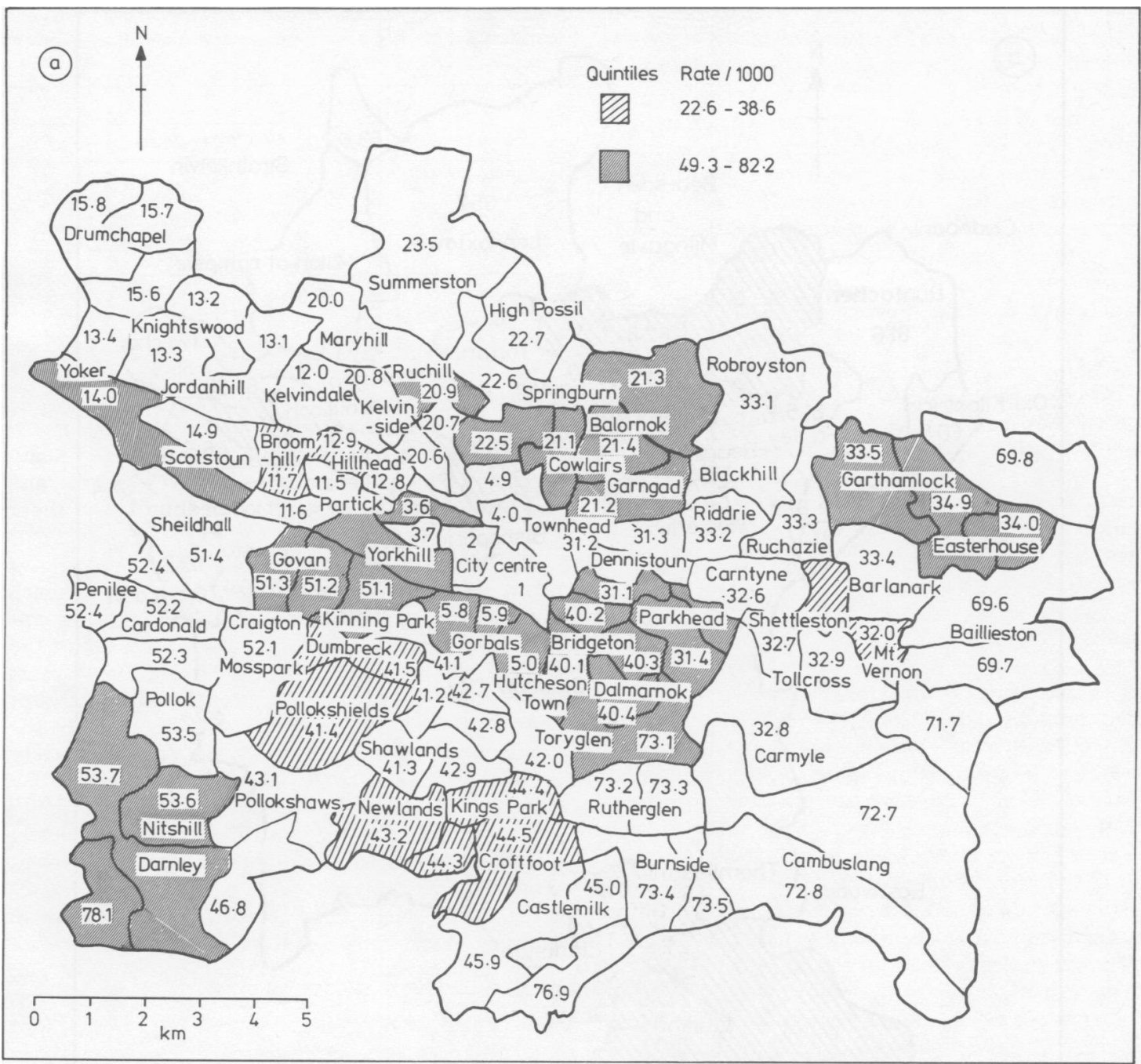

Fig 1 Mortality from all causes. Deaths per 1000 men and women aged 60-79 years (1980-2): (a) Glasgow City; (b) outlying local government districts. Numbers refer to postcode sector with a prefix removed.

sectors with the lowest mortality. The geographical variation in death rates for the older age group (60-79 years) is shown in figure 1 .

In order to provide a comparison with the younger population, fig 2 shows the standardised mortality rates (SMR) by postcode sector for the population in the 15-59 year age group. The SMR for those postcode sectors in the highest quintile for mortality is on average about 2.5 times that for those in the lowest quintile-slightly greater than in the older age groups. There is close correspondence between figs 1 and 2: there is a strong tendency for those areas with the highest death rates in the older age groups also to have high death rates in the younger age groups, and the same consistency is observed for all the areas with low death rates. It is evident therefore that those who reside in areas with high death rates and reach pensionable age still have a reduced expectation of life compared with those who live in areas with low death rates.

The areas with high death rates are located entirely in the more disadvantaged areas of the city and suburbs (although not all of what appear to be the most disadvantaged areas are in the highest death rate category), and the low death rate areas are found in the more affluent parts, mainly outside the city. 


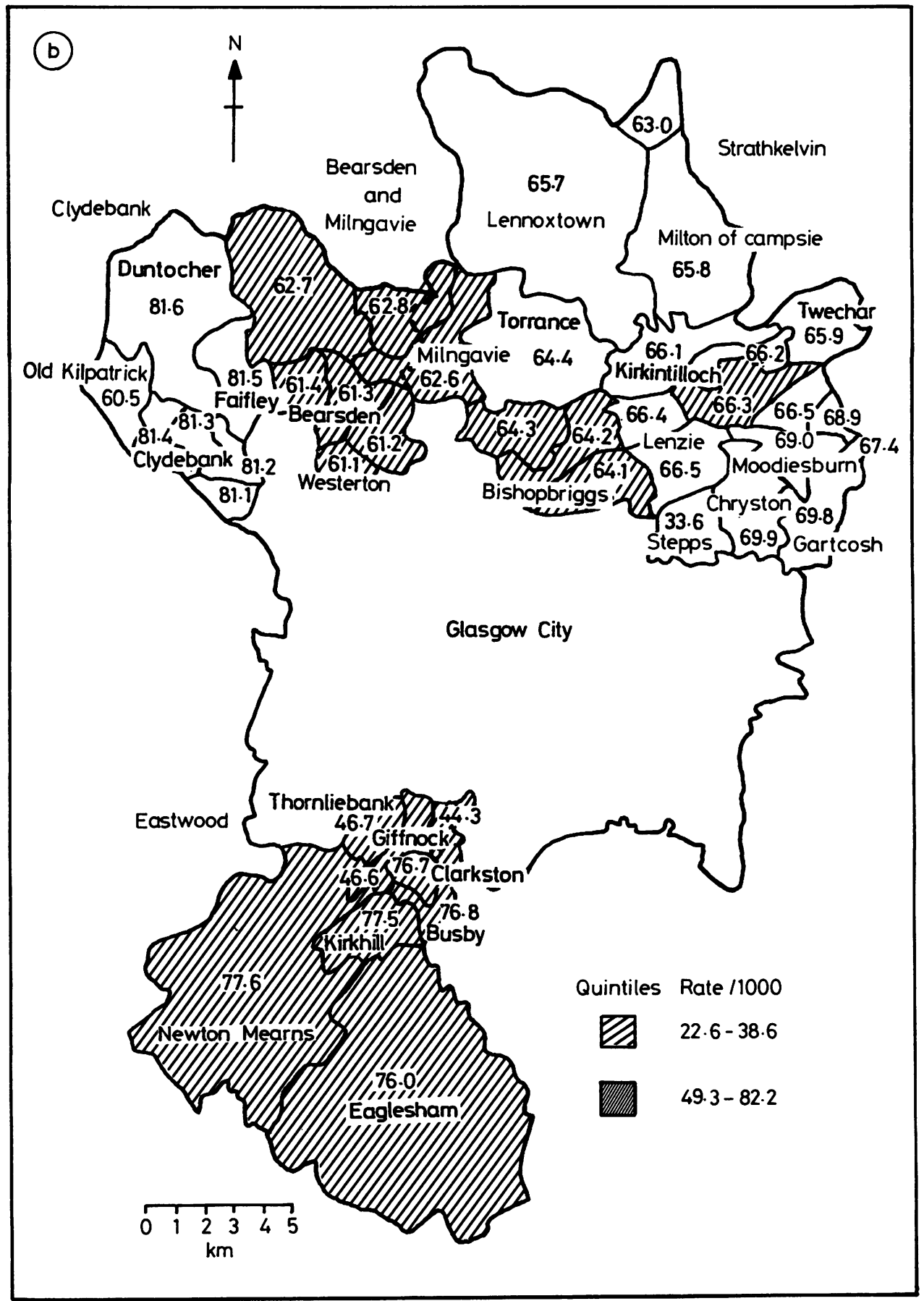

Fig 1b 


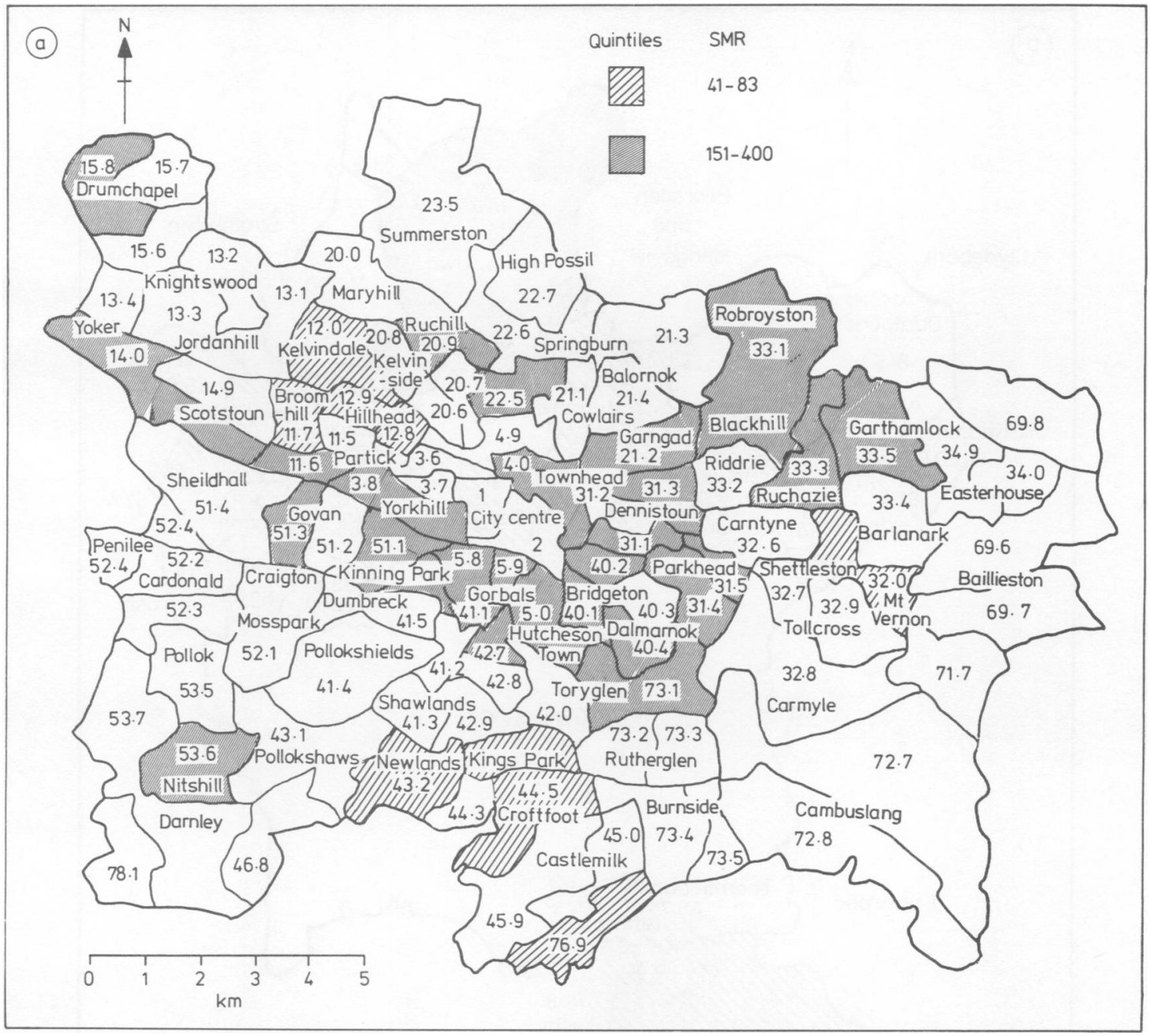

Fig 2 Mortality from all causes. SMR values for males and females aged 15-59 years (1980-2): (a) Glasgow City; (b) outlying local government districts. Numbers refer to postcode sector with a prefix removed.

Table 2 Socioeconomic characteristics of the population resident in the postcode sectors in the highest and lowest quintiles of mortality, census 1981

\begin{tabular}{|c|c|c|}
\hline \multirow[b]{2}{*}{ Census indicator } & \multicolumn{2}{|l|}{ Mortality rating } \\
\hline & Highest quintile & Lowest quintile \\
\hline $\begin{array}{l}\% \text { children }<16 \text { yr living in single } \\
\text { parent households }\end{array}$ & $6 \cdot 0 \quad(0 \cdot 2-7 \cdot 1)$ & $26 \cdot 0(22 \cdot 7-51 \cdot 8)$ \\
\hline$\%$ unemployed men $(16-64 \mathrm{yr})$ & $30 \cdot 8(19 \cdot 2-45 \cdot 9)$ & $6 \cdot 1(3 \cdot 3-15 \cdot 3)$ \\
\hline$*_{1}$ housing owned by local authority & $72 \cdot 7(0 \cdot 1-48 \cdot 5)$ & $17 \cdot 4(18 \cdot 3-96 \cdot 2)$ \\
\hline$\%$ overcrowded households ${ }^{*}$ & $26 \cdot 2(17 \cdot 2-41 \cdot 1)$ & $7 \cdot 7 \quad(2 \cdot 6-17 \cdot 5)$ \\
\hline$\%$, population social classes IV and V & $43 \cdot 5(8-84)$ & $7 \cdot 9(2-15)$ \\
\hline
\end{tabular}

Figures in parentheses indicate the ranges for the 22 postcode sectors in each quintile.

-Defined as greater than one person per room
Table 2 illustrates the socioeconomic characteristics of the population quintiles with the lowest and highest death rates with reference to five indicators derived from the 1981 census. The extreme difference between the two types of area is evident from the table. The postcode sectors with the highest mortality rates have an average five times the rate of unemployment in men, over five times the proportion of the population in social classes IV and $\mathrm{V}$, about four times the proportion of local authority housing and of overcrowded households, and three times the prevalence of children living in single parent households. 


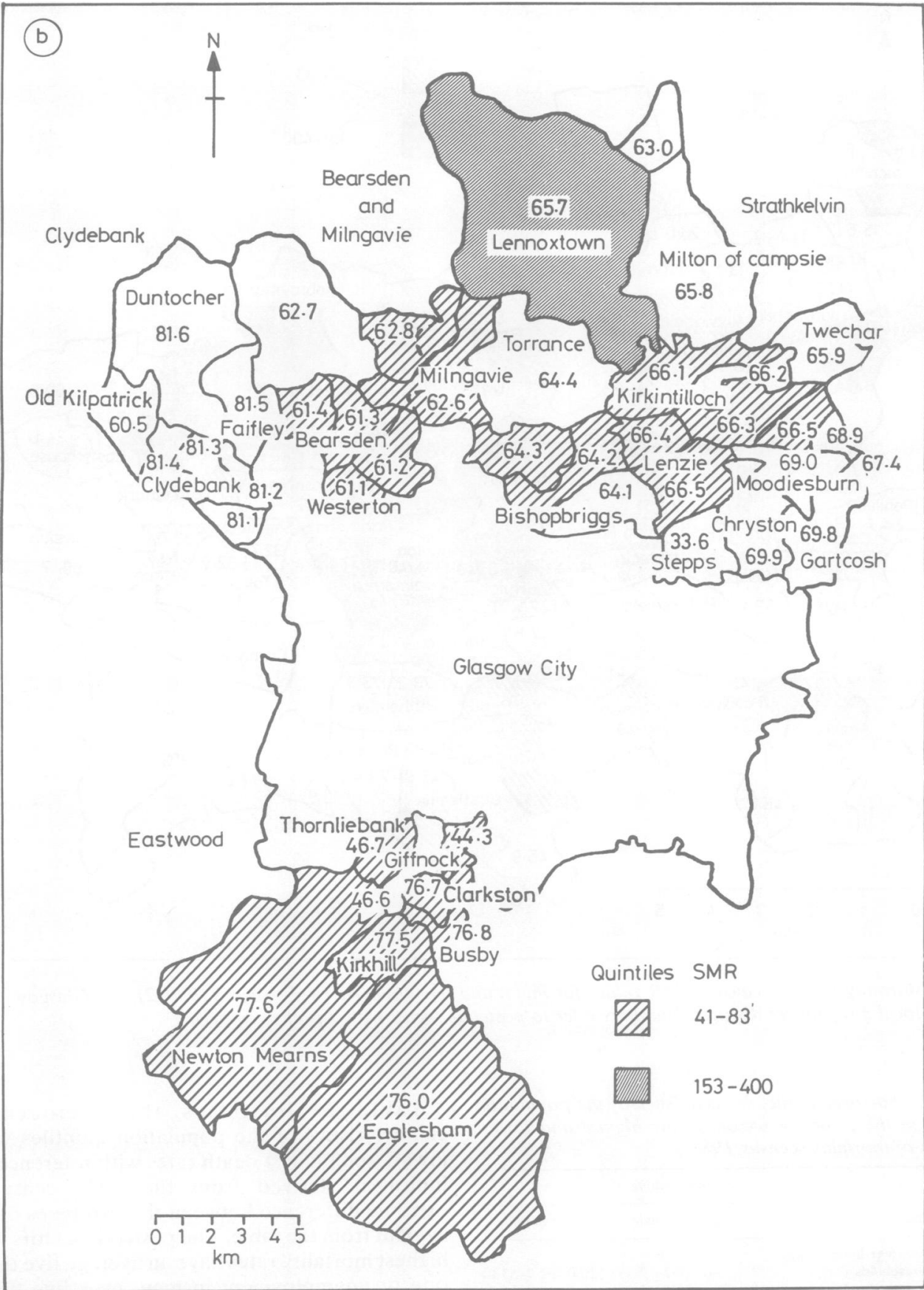

Fig 2b 
For the 16-64 age group of men the SMR for social class $\mathrm{V}$ exceeds that for social class $\mathrm{I}$ by a factor of 1.8 (SMR 137:77). ${ }^{1}$ For the population aged 65-84 years and resident within the Greater Glasgow Health Board area, the difference in death rates between the $20 \%$ of the population resident in areas with the lowest and highest SMRs is about $1 \cdot 8$. For younger people the difference is somewhat greater $(2 \cdot 2$ for the 60-64 year age group; $2 \cdot 5$ for the $15-59$ year age group). The magnitude of these geographical differences is perhaps surprising for several reasons. Firstly, they apply to a considerably larger proportion of the population than do the social class differences (20\% in each group compared with less than $5 \%$ of the population in each of the social classes I and V). Secondly, postcode sectors are not designed to be homogeneous areas in terms of socioeconomic housing and environmental characteristics. This will tend to diminish the observable range of health characteristics (such as mortality) that is associated with these characteristics. Thirdly, it is remarkable (but consistent with the findings of Fox, Goldblatt, and Jones) ${ }^{2}$ that these geographical differences in death rates can be demonstrated even at 80-84 years of age. The observed geographical variation is of course much less than occupational differentials in mortality; ${ }^{1}$ but geographical differences are important because they do provide a more feasible basis for preventive or other appropriate public health activity.

It is unlikely that a major part of these differences in death rates can be attributed simply to lack of health service resources: hospital services $^{3}$ and probably general practitioner services ${ }^{4}$ are utilised considerably more heavily by populations resident in more disadvantaged areas. One possible explanation is differential migration: the fitter people are likely to leave undesirable areas, whereas the less fit may 'gravitate' to them. The main reason, however, must lie in the very different circumstances in which the disadvantaged and more prosperous people live-in their lifestyle, socioeconomic characteristics, and possibly their environment. And, since clear geographical differences in mortality may be demonstrated until at least age 84 years, these different circumstances are likely to persist throughout life, it being perhaps unlikely that adverse influences confined to the early or middle years of life would still result in higher mortality in old age.

In an attempt to improve health generally, Glasgow District Council, Strathclyde Regional Council, and the Greater Glasgow Health Board have established the campaign to make Glasgow a no-smoking city by the year 2000 , and the Health Board has embarked on a programme to reduce heart disease and strokes by $10 \%$ over the next ten years. Health centres have also been built in most of the disadvantaged areas. However, the differences in health between the poor and the more affluent areas can be reduced only by somehow breaking into the cycle of poverty, low educational attainment, unemployment, and environmental problems. This will require further vigorous collaborative activity among the various agencies involved in local government and health, and will almost certainly require some reallocation of resources to those communities that are most in need.

\section{References}

${ }^{1}$ Registrar General. Occupational mortality 1970-2 Decennial supplement, Series DS No. 1. London: HMSO, 1978.

${ }^{2}$ Fox AJ, Goldblatt PO, Jones DR. Social class mortality differentials: Artefact, selection or life circumstances? J Epidemiol Community Health 1985; 39: 1-8.

${ }^{3}$ Townsend P, Davidson N. Inequalities in health, The Black Report. Harmondsworth: Penguin Books, 1982.

${ }^{4}$ Royal College of General Practitioners. Social class and health status: Inequality or difference. Occasional paper No. 25. Exeter: Royal College of General Practitioners, 1984. 